\title{
CLINICAL APPLICATION OF MAGNETIC RESONANCE IN ACUTE TRAUMATIC BRAIN INJURY
}

\author{
Dionei F. Morais ${ }^{7}$, Antonio R. Spotti ${ }^{2}$, Waldir A. Tognola ${ }^{3}$, Felipe F.P. Gaia ${ }^{4}$, Almir F. Andrade
}

\begin{abstract}
Purpose: To evaluate the clinical applications of magnetic resonance imaging (MRI) in patients with acute traumatic brain injury (TBI): to identify the type, quantity, severity; and improvement clinical-radiological correlation. Method: Assessment of 55 patients who were imaged using CT and MRI, 34 (61.8\%) males and 21 (38.2\%) females, with acute ( 0 to 5 days) and closed TBI. Results: Statistical significant differences (McNemar test): ocurred fractures were detected by $\mathrm{CT}$ in $29.1 \%$ and by MRI in $3.6 \%$ of the patients; subdural hematoma by $\mathrm{CT}$ in $10.9 \%$ and $\mathrm{MRI}$ in $36.4 \%$; diffuse axonal injury (DAI) by CT in $1.8 \%$ and MRI in $50.9 \%$; cortical contusions by $\mathrm{CT}$ in $9.1 \%$ and MRI in $41.8 \%$; subarachnoid hemorrhage by $\mathrm{CT}$ in $18.2 \%$ and MRI in $41.8 \%$. Conclusion: MRI was superior to the $\mathrm{CT}$ in the identification of DAI, subarachnoid hemorrhage, cortical contusions, and acute subdural hematoma; however it was inferior in diagnosing fractures. The detection of DAI was associated with the severity of acute TBI.
\end{abstract}

KEY WORDS: magnetic resonance imaging, traumatic brain injury.

\begin{abstract}
Aplicação clínica da ressonância magnética em pacientes com traumatismo craniencefálico agudo
Resumo - Propósito: Avaliar a aplicação clínica da ressonância magnética (RM) em pacientes vítimas de traumatismo craniencefálico (TCE) agudo, na identificação do tipo, número, gravidade e correlação clínicaradiológica. Método: Foram estudados prospectivamente 55 pacientes vítimas de TCE agudo fechado (0-5 dias), por TC e RM, sendo 34 do sexo masculino e 21 do feminino. Resultados: Houve diferença estatisticamente significante (teste McNemar): fraturas de crânio foram detectadas em 29,1\% pacientes na TC e 3,6\% pela RM; hematoma subdural $10,9 \%$ na TC e $36,4 \%$ pela RM; lesão axonal difusa (LAD) $1,8 \%$ pela TC e $50,9 \%$ na RM; contusões corticais $9,1 \%$ na TC e 41,8\% pela RM, hemorragia subaracnóidea $18,2 \%$ na TC e $41,8 \%$ pela RM. Conclusão: A RM foi superior à TC na identificação da LAD, hemorragia subaracnóidea, contusões corticais e hematoma subdural agudo, porém inferior no diagnóstico de fraturas. A detecção de LAD pela RM foi associada com maior gravidade do TCE agudo.
\end{abstract}

PALAVRAS-CHAVE: ressonância magnética, traumatismo craniencefálico.

Traumatic brain injury (TBI) is one the most frequent causes of the world's morbimortality'. It turns productive and young individuals into dependent patients who usually require decades of specialized and highly expensive care. For these reasons it is essential to define in a more precise way the true extension of the initial encephalic damage, so that the different types of traumatic lesions are understood, to enable better treatment. Neurological assessment of the traumatized patients consists mainly in the analysis of motor activity, of the pupillary reflex and of the consciousness level ${ }^{2}$. Variations in the level of consciousness constitute the best indicator of the brain's global function. The assessment of the level of conscious- ness determined by the Glasgow coma scale is a guide for conduct and selection of diagnostic exams ${ }^{3}$.

Neuroimaging allows accurate diagnostic information that will set subsidies for therapeutic conduct. The computerized tomography of the skull (CT) has been used as the preferred method in the initial investigation of the $\mathrm{TB}^{4-6}$. The use of encephalic magnetic resonance imaging (MRI) may offer useful information due to its high sensitivity to reveal non-hemorrhagic and hemorrhagic traumatic lesions, to help in the understanding of the pathophysiology of a traumatic brain injury, besides better assessing the long-term prognostics of the lesions and its consequences ${ }^{7}$. Considering the multiplanar capacity, cost

Departamento de Ciências Neurológicas, Faculdade de Medicina de São José do Rio Preto, São José do Rio Preto SP, Brazil (SJRP): 'Professor Assistente, Serviço de Neurocirurgia do Hospital de Base, SJRP; ${ }^{2}$ Professor Adjunto Doutor do Departamento de Ciências Neurológicas - FAMERP, SJRP; ${ }^{3}$ Professor Adjunto Livre Docente do Departamento de Ciências Neurológicas - FAMERP, SJRP; ${ }^{4}$ Residente do Serviço de Neurocirurgia do Hospital de Base, SJRP; ${ }^{5}$ Professor Adjunto Livre Docente do Departamento de Neurocirurgia - Emergência, HC/FMUSP-SP.

Received 17 August 2007, received in final form 9 November 2007. Accepted 11 December 2007.

Dr. Dionei Freitas de Morais - Avenida José Munia 4850 - 15090-500 São José do Rio Preto SP - Brasil. E-mail: centro@cerebroecoluna.com.br 
reduction of the equipment and exams, faster time in the acquisition of the image, development of new sequences such as the T2* "ecoplanar" gradient, FLAIR and diffusion, few bone artifacts and capacity of assessing encephalic trunk, cranial nerves and rear fossae allow the MRI to be used in the acute phase of the $\mathrm{TBI}^{8,9}$.

The goal of this study was to evaluate the clinical application of MRI on patients with acute TBI, to better identify the type, quantity and severity of the encephalic lesion.

\section{METHOD}

From January 2002 to June 2005, 55 patients, victims of closed acute traumatic brain injury, were prospectively studied, treated at the Emergency Service of Hospital de Base (a teaching hospital) de São José do Rio Preto - SP, subjected to clinical assessment and handling according to the norms of Advanced Trauma Life Support (ATLS $\left.{ }^{\circledR}\right)^{2}$ followed by neurological assessment and initial CT.

According to the Glasgow Coma Scale (GCS) modified by Stein and Ross ${ }^{10}$, the traumatic brain injury was classified as mild, moderate and severe.

Within 5 days after the trauma, only the patients with consciousness neurological alteration (Glasgow $<15$ ) and focal deficit that did not require immediate neurosurgery were subjected to the exam through MRI.

This study was approved by the Committee of Ethics in Research (CER) of the São José do Rio Preto Medical School (FAMERP).

The reports were issued by radiologists from the Radiology Services of Hospital Base de São José do Rio Preto - SP, and were revised by a neuro-radiologist from Hospital Beneficência Portuguesa de São Paulo, SP.

The CT exam of the skull and the brain was performed on a Philips Tomoscan SR 4000 (Philips Medical Systems, Best, Holland) machine on a table with axial support for the head resting the patient on a dorsal decubitus with the image of the skull on profile and slant of the orbit-meatal line. The protocol includes images through CT in axial cuts of the rear fossae $(5 / 5$ $\mathrm{mm})$, supratentorial $(10 / 10 \mathrm{~mm}$ ) and of the bone window of the whole brain.

The encephalic MRI exam was performed on a Philips Gyroscan Intera T15 de 1.5 Tesla (Philips Medical Systems, Best, Holland) machine with the patient positioned on the examination table on a dorsal decubitus, using a head coil, keeping himself / herself immobile and breathing normally.

The protocol includes images through MRI on the sequences spin-eco turbo axial in the T2 weighting, Epi axial in the T2*, FLAIR axial in the T2, axial in the diffusion and spin turbo sagittal in the $\mathrm{T} 1$.

Restless patients and those who were in a coma were given sedation (midazolan, propofol) on anesthetic induction to take the images.

Patients above 12 years of age, stable on the cardiovascular and respiratory systems, and without devices such as pace- makers, intra-ocular projectiles and surgical clips or fire or cutting and thrusting weapon wounds were included in the present study.

In the comparative study of the lesions through the CT and MRI, the McNemar test ${ }^{11}$ was used.

To verify the possible association between the GCS and the two levels: mild or moderate/severe and the variables acute subdural hematoma, diffuse axonal lesion, cortical contusions, and subarachnoid hemorrhage, the chi-square test was applied.

To compare medians between the diagnostic methods through imaging (CT and MRI), the Signal test was used for the variables: quantity of cortical contusions, time and quantity of lesions".

The level of significance adopted was $\alpha=0.05$. All the calculations and analysis were performed using the Minitab program for Windows, version $14.13^{12}$.

\section{RESULTS}

The sample consisted of 55 patients victims of acute $\mathrm{TBI}$, with the age ranging from 13 to 83 years old (34.2 \pm 17.4 years old), with $34(61.8 \%)$ from the masculine and 21 (38.2\%) from the feminine gender treated between January 2002 and June 2005. By the score of the GCS modified by Stein and Ross ${ }^{10}, 14$ (25.5\%) patients were classified as severe, 25 (45.4\%) as moderate and the remaining $16(29.1 \%)$ as mild.

In this study the following lesions of the acute TBI were studied through CT and MRI: skull fracture (Fract), extradural hematoma (EDH), acute subdural hematoma (ASDH), subdural hygroma (Hygr), diffuse axonal injury (DAI), cortical contusions ( $C t-c)$, intraparenchymal hematoma (IPH), subarachnoid hemorrhage (SAH), intraventricular hemorrhage (IVH), diffuse cerebral swelling (DCS), hemispherical cerebral swelling (HCS), ischemia (Isch) (Table 1).

In this study, the MRI was superior to the CT in diagnosing DAI, CT and ASDH; however it was inferior in diagnosis fractures $(p<0.0005)$.

The analysis of the relationship of dependency among diagnosis through MRI and ASDH, DAI, Ct-c and SAH with the levels of severity by the GCS for mild or moderate/ severe TBI by the chi-squared test (Table 2).

With respect to the quantity of lesions, the amount detected in the CT varied from 0 to 5 , while in the MRI the range was from 0 to 8 . On average, 1.4 lesions were found by the CT with standard deviation of 1.27. The same calculus for the MRI data revealed an average of 3.2 with standard deviation of 1.82 .

The median values denote that MRI detected 2 more lesions per patient than the CT $(\mathrm{p}<0.0001)$.

The time of acquisition of images through CT and MRI had the same range, i.e., from 0 to 5 days. The average time for the CT was 2.4 days with a standard deviation of 1.72 days. Likewise, for the MRI the average time was 
Table 1. Frequency and percentage of the patients whose lesion was diagnosed in each exam separately (CT or MRI); in both exams simultaneously (CT and MRI); and value of P for the McNemar test.

\begin{tabular}{lcccc}
\hline Lesion & $\begin{array}{c}\mathrm{CT} \\
\mathrm{n}(\%)\end{array}$ & $\begin{array}{c}\mathrm{MRI}(\%) \\
\text { Fract }\end{array}$ & $\begin{array}{c}\mathrm{CT} \text { and MRI } \\
\mathrm{n}(\%)\end{array}$ & $\mathrm{P}$ \\
EDH & $4(7.3)$ & $2(3.6)$ & $2(3.6)$ & $* 0.0005$ \\
ASDH & $6(10.9)$ & $20(36.4)$ & $3(5.5)$ & $* 0.0037$ \\
Hygr & $1(1.8)$ & $2(3.6)$ & $0(0.0)$ & $\mathrm{NC}$ \\
DAI & $1(1.8)$ & $28(50.9)$ & $1(5.5)$ & $*<0.0005$ \\
Ct-C & $5(9.1)$ & $23(41.8)$ & $5(9.1)$ & $*<0.0005$ \\
IPH & $3(5.5)$ & $2(3.6)$ & $1(1.8)$ & $\mathrm{NC}$ \\
SAH & $10(18.2)$ & $23(41.8)$ & $8(14.6)$ & $* 0.0036$ \\
IVH & $1(1.8)$ & $5(9.1)$ & $1(1.8)$ & 0.1336 \\
DCS & $5(9.1)$ & $1(1.8)$ & $0(0.0)$ & 0.2207 \\
HCS & $3(5.5)$ & $0(0.0)$ & $0(0.0)$ & 0.25 \\
Isch & $4(7.3)$ & $8(14.6)$ & $3(37.5)$ & 0.2207 \\
\hline
\end{tabular}

*Significant difference; NC, McNemar test may be faulty or not conclusive; Fract, skull fracture; EDH, extradural hematoma; ASDH, acute subdural hematoma; Hygr, subdural hygroma; DAI, diffuse axonal injury; Ctc, cortical contusions; IPH, intraparenchymal hematoma; SAH, subarachnoid hemorrhage; IVH, intraventricular hemorrhage; DCS, diffuse cerebral swelling; HCS, hemispherical cerebral swelling; Isch, ischemia.

2.5 days with a standard deviation of 1.59 days. In terms of median values, a difference of one day between the $\mathrm{CT}$ and the MRI is observed, being 2 days for the TC and 3 days for the MRI to be done.

The results for the time gap between the exams indicate that the period between one exam and the other did not exceed 1 day, whereas in $24(43.6 \%)$ of the patients it was performed on the same day; in $11(20 \%)$ the
CT was performed prior to the MRI; and in 20 (36.4\%) the MRI was performed prior to the CT. Through the Signal test $(p=0.1496)$.

\section{DISCUSSION}

In the present research, the most important clinical application of the magnetic resonance in patients with acute TBI was the precise identification of intra-axial (diffuse axonal lesion, cortical contusions) and extra-axial (acute subdural hematoma and subarachnoid hemorrhage) encephalic lesions; it was also possible to detect the greater quantity of lesions. With respect to the clinicradiological correlation, there was only significant association between diffuse axonal lesions detected by the MRI and moderate/serious TBI according to the GCS. For skull fractures, the $\mathrm{CT}$ was superior to the MRI in diagnosing this lesion.

In this study, the CT showed this type of lesion (skull fractures) in 16 (29.1\%) patients while the MRI detected it only in 2 (3.6\%); one of them presented an adjacent cortical lesion. It is also important to consider that even very long traces of fracture might not be evidenced on the CT if they are parallel to the plan of the cutting. Therefore, the normal CT did not exclude, definitely, the existence of linear fractures.

Acute subdural hematoma: found in 10 to $20 \%$ of the patients victims of TBI, occurring in up to $30 \%$ of the fatal lesions ${ }^{13}$. Although the $C T$ is also the preferred exam during the acute phase of the TBI, it shows limitations to demonstrate small subdural collections that protect themselves along the cranial vault such as ${ }^{13-15}: 1$ ) attenuation artifacts of the $\mathrm{X}$-rays through the bony structures tend to darken them; 2 ) when the exam is documented

Table 2. Frequency and percentage (chi-square test) to assess the relation between MRI diagnosis and the severity of TBI.

\begin{tabular}{|c|c|c|c|c|c|}
\hline MRI (diagnosis) & Chi-square test & Mild TBI & Moderate/severe TBI & Total & $P$ \\
\hline \multirow[t]{3}{*}{ ASDH } & Yes & $6(37.5 \%)$ & $14(35.9 \%)$ & $20(36.4 \%)$ & \\
\hline & No & $10(62.5 \%)$ & $25(64.1 \%)$ & $35(64.6 \%)$ & \\
\hline & Total & 16 & 39 & 55 & 0.911 \\
\hline \multirow[t]{3}{*}{ DAI } & Yes & $2(12.5 \%)$ & $26(66.7 \%)$ & $28(50.9 \%)$ & \\
\hline & No & $14(87.5 \%)$ & $13(33.3 \%)$ & 27 (49.1\%) & \\
\hline & Total & 16 & 39 & 55 & $*<0.0001$ \\
\hline \multirow[t]{3}{*}{ Ct-c } & Yes & $7(43.8 \%)$ & $16(41.0 \%)$ & $23(41.8 \%)$ & \\
\hline & No & $9(56.3 \%)$ & $23(59.0 \%)$ & $32(58.2 \%)$ & \\
\hline & Total & 16 & 39 & 55 & 0.105 \\
\hline \multirow[t]{3}{*}{ SAH } & Yes & $4(25.0 \%)$ & 19 (48.72) & $23(41.8 \%)$ & \\
\hline & No & $12(75.0 \%)$ & $20(51.28 \%)$ & $32(58.2)$ & \\
\hline & Total & 16 & 39 & 55 & 0.105 \\
\hline
\end{tabular}

*Significant difference; ASDH, acute subdural hematoma; DAI, diffuse axonal injury; Ct-c, cortical contusions; SAH, subarachnoid hemorrhage. 
with parameters that are adequate for the demonstration of soft parts (brain) the image of the hematoma may be confused with the one of the bony structures; 3 ) hematomas located below the temporal or occipital lobes, below the tentorium cerebelli and in the convexity, when small, tend to be darkened by the partial volume with the bone.

Inter-hemispheric acute subdural hematomas occur in adults who suffer trauma involving the whip mechanism (whiplash) or children who suffer lesions by a mechanism that is similar to spanking occasions. Although the $C T$ is useful in the initial assessment of these patients, the MRI is more sensitive to detect small subdural collections that indicate the possibility of child beating and domestic violence ${ }^{16,17}$. The most sensitive sequences to detect this lesion are FLAIR and T2*.

For "laminate" acute subdural hematoma, the CT detected only $6(10.9 \%)$ and the MRI $20(36.4 \%)$ patients. Through McNemar's test, the difference was significant. The MRI was more sensitive and detected this lesion in $86.95 \%$ of the patients, using the association of the sequences T1, T2, FLAIR, T2* and diffusion.

Diffuse axonal injury: intra-axial lesion that along with the cortical contusions, represent the most important cause of morbid-mortality in patients with traumatic brain lesions ${ }^{13,15}$. The diagnosis is based upon the clinical condition and on the imaging exams (CT and MRI). Clinically, DAl is defined as an estate of immediate coma to the impact lasting more than 6 hours, that does not result in expansive lesion (hematomas) or anoxic-ischemic lesions ${ }^{18}$. Its severity is graded according to the duration of the coma and the presence of signs of the impairment of the brainstem ${ }^{19}$.

At the present study, the DAI was identified by the CT in only $1(1.8 \%)$ patient and in $28(50.9 \%)$ by the MR. Through the McNemar's test there was a statistically significant difference between the CT and the MRI, showing that MRI is more indicated when it comes to detecting and characterizing DA $\mathrm{I}^{20}$.

The initial CT on the patient who suffered DAI is usually normal despite the severity of the clinical condition, only 25 to $50 \%$ of the patients with DAI showed abnormalities on this exam ${ }^{13}$. Computed tomographies performed on subsequent dates may show lesions that were not visible on the initial exam. These lesions, on the acute phase, are seen as little hyper-dense petechial hemorrhages, particularly at the point of convergence of white substance/grey substance at the rostral portion of the midbrain and at the corpus callosum ${ }^{8,20}$.

Showing the value of the MRI on the acute TBI, Mittl et al. ${ }^{21}$ investigated 20 patients with light TBI in which the CT had not detected any abnormality. The MRI was performed in the sequences $\mathrm{T} 2$ and $\mathrm{T} 2$ * for 4 days, showing abnormality compatible to a diffuse axonal injury in $6(30 \%)$ patients.

In this investigation, the presence of diffuse axonal lesion on the MRI was related to a moderate or severe TBI ( $G l<14$ ), where 26 patients $(66.7 \%)$ out of the 39 with this score presented DAI. Within those with mild TBI, only 2 (12.5\%) presented DAI through MRI. These results are concordant with the ones obtained by Tokutomi et al. ${ }^{22}$, who studied 120 patients victims of closed, mild, moderate, and severe TBI with MRI using the sequences $\mathrm{T} 1, \mathrm{~T} 2$, and FLAIR. The authors verified that in 44 patients with mild TBI, only $1(2 \%)$ presented signal alteration on the corpus callosum; only 3 patients (10\%) out of the 31 with moderate TBI presented this alteration; 17 patients (38\%) out of 45 with severe TBI had signal alteration on the corpus callosum compatible with DAI.

Paterakis et al. ${ }^{23}$ performed studies with an MRI in the sequences $\mathrm{T} 1, \mathrm{~T} 2, \mathrm{~T} 2^{*}$, and FLAIR with 33 patients with acute and closed TBI in which the CT had not detected abnormalities. In this study, the DAI was found by the MRI in 24 patients, where 19 have severe $\mathrm{TBI}(\mathrm{Gl}<8)$ and 5 have moderate TBI (Gl=9-12). They show that MRI is more sensitive than the $\mathrm{CT}$ in the detection of hemorrhagic and non-hemorrhagic axonal lesions, whereas the presence of hemorrhage is related to the worst prognostics. These results are according to those obtained at the present study, especially those related to the highest occurrence of DAI in victims of severe and moderate TBI.

The diffuse axonal lesion is the most frequently anatomic-pathological finding detected in about $80 \%$ of the patients who were fatal victims of traffic accidents ${ }^{24,25}$. When studied by the $\mathrm{CT}$, only larger hemorrhagic lesions were seen'. The magnetic resonance imaging has shown more sensitivity in the detection and characterization of these lesions ${ }^{9,21,22}$. By using MRI in the present study it was possible to evidence the DAI in about $51 \%$ of the patients, while the $\mathrm{CT}$ detected it in only $2 \%$, with MRI being superior in relation to the majority of the projects consult$\mathrm{ed}^{9,21,22}$. Furthermore, a direct correlation of the presence of this lesion with the severity of the GCS was established. Similar findings were found in the literature ${ }^{9,26}$.

Cortical contusions ( $\mathrm{Ct}-\mathrm{c}$ ): In the initial CT, the findings are usually subtle or nonexistent including badly defined areas of smaller streaky density to small hyper dense focus of petechial hemorrhages. In the CT performed 24 or 48 hours after the trauma, lesions are more often observed than in the initial trauma. In $20 \%$ of the cases, late hemorrhages occur in areas that are previously hypodense and non-hemorrhagic ${ }^{20}$. The edema and the effect of mass 
typically increase in the first days after the trauma and then decrease gradually over time. Cortical contusions may impregnate themselves through the contrast ${ }^{27}$.

The MRI is much more sensitive than the CT when detecting the presence and extension of the cortical contusions. It is observed the presence of multiple superficial areas that are poorly delimited and appear frequently heterogeneous, as on the images weighed in $\mathrm{T} 1$ and $\mathrm{T} 2^{8,16}$. In the acute phase, the FLAIR sequence is the one which best demonstrates the hyper-signal of the swelling on the cortical and the $\mathrm{T}^{*}$ the hypo-signal of the focuses of hemorrhages of the contusion ${ }^{24}$.

In relation to the cortical contusions, the MRI was more sensitive when detecting, characterizing and quantifying the primary traumatic lesions. Moreover, the results showed there was no relationship of dependency between the Ct-m and the severity in the GCS score. These results are similar to those found by other researchers $3,8,9,15,16,20$.

Subarachnoid hemorrhage appears with a thin collection of blood on the subarachnoid space between the pia mater and the arachnoid mater. It is usually focal along the area of contusion, $A S D H$, laceration, fracture or diffuse in the arachnoid space and basal cisterns (interpeduncular cisterns). This lesion was found by CT in 10 (18.2\%) patients and in 23 (41.8) by MRI. The superiority evidenced by MRI is due to the performance of the FLAIR sequence that is more sensitive when detecting the traumatic $\mathrm{SAH}^{24,28,29}$.

On CT, SAH appears as hyper dense images in relation to the brain tissue along the furrows and cisterns. This method is considered to be superior to the conventional MRI $(T 1, T 2)$ in detecting this lesion. However, with the development of new sequences such as FLAIR, that suppresses the cerebrospinal fluid of the subarachnoid space, it was possible to better visualize $\mathrm{SAH}$ than with $\mathrm{CT}$ carefully performing the exam with oxygen at 40 to $50 \%$ more room air or with nitrous oxide, because the oxygen at $100 \%$ would leave the subarachnoid space whitish, with the possibility of super-estimating the diagnostic of the $\mathrm{SAH}^{30}$.

On MRI, the subarachnoid hemorrhage may be better detected than by $\mathrm{CT}$, mainly on FLAIR sequences through signal hyper-intensity and on ecoplanar gradient through signal hypo-intensity.

There was no statistical difference on the intraventricular hemorrhage, diffuse and hemispherical brain swelling and on the ischemia diagnosis. Moreover, it was not conclusive for extradural hematoma, subdural hygroma, intraparenchymal hematoma, due to the size of the sample and the number of patients with these lesions.

TBI cause great morbidity producing deficiencies on the information process when assessed by neurophysi- ologic tests. The severity of the brain lesion should not be evaluated exclusively by the extension of the loss as determined on the neuropsychological tests; methods of diagnosis through imaging must also be used to detect anatomic and physiological abnormalities of the brain tissue ${ }^{31}$.

Many different MRI sequences have been applied to the assessment of closed TBI. The ecoplanar gradient sequence at the $\mathrm{T}^{*}$ weighing contributed to demonstrate chronic and acute intra-axial hemorrhage ${ }^{32}$. The utility of FLAIR images in diagnosing swelling and subarachnoid hemorrhage was studied by many researchers ${ }^{28,29,33}$. New discoveries of images through diffusion (diffusion-weighted, apparent diffusion coefficient, diffusion tensor imaging) besides demonstrating diffuse axonal and ischemic lesions better, also indicate the prognostic more precisely $y^{34-37}$.

In the present study, the magnetic resonance imaging was superior to the computerized tomography in diagnosing the diffuse axonal injury, subarachnoid hemorrhage, multiple contusions and laminate acute subdural hematoma, though inferior to diagnosing fractures.

The magnetic resonance imaging detected a greater number of traumatic lesions and its greatest utility is diagnosing the diffuse axonal injury. The presence of DAl is associated with greater severity of the acute traumatic brain injury.

\section{REFERENCES}

1. Kraus JF, McArthur DL, Silverman TA, Jayaraman M. Epidemiology of brain lesion In: Narayan RK, Wilberger JE, Povishock JT (Eds). Neurotrauma. New York: McGraw-Hill; 1996;13-30.

2. Comitê de Trauma do Colégio Americano de Cirurgiões. Suporte Avançado de Vida no Trauma (SAVT - ATLS $\left.{ }^{\circledR}\right), 6^{\text {a }}$ Ed. Illinois: American College of Surgeons; 1997.

3. Teasdale G, Jennett B. Assessment of coma and impaired consciousness. Lancet 1974;2:81-83.

4. Gentry LR. Imaging of closed head lesion. Radiology 1994;191:1-17.

5. Toyama Y, Kobayashi T, Nishiyama Y, Satoh K, Ohkawa M, Seki K. CT for acute stage of closed head lesion: review. Radiation Med 2005;23:309316.

6. Andrade AF, Almeida AN, Bor-Seng-Shu E, Lourenço L, Mandel M, Marino R Jr. The value of cranial computed tomography in high-risk, midly head-injured patients. Surg Neurol 2006;65:10-13.

7. Gean AD. Traumatic brain lesion: imaging update 2004; http: / / www nordictraumarad.com/Syllabus04/gean.pdf.

8. Gentry RL, Godersky JC, Thompson B, Dunn VD. Prospective comparative study of intermediate-field MR and CT in the evaluation of closed head trauma. AJR 1988;150:673-682.

9. Gentry RL, Thompson B, Godersky JC. Trauma to the corpus callosum: MR features. AJNR 1988;9:1129-1138.

10. Stein SC, Ross SE. Moderate head lesion: a guide to initial management. J Neurosurg 1992;77:562-564.

11. Zar JH. Biostatistical analysis. $4^{\text {th }}$ Ed. New Jersey: Prentice Hall 1999.

12. Minitab, lnc. Minitab statistical software ${ }^{\mathrm{TM}}$, Release 14.13. Copyright $C 2004$.

13. Osborn AG. Traumatismo craniencefálico. In Osborn AG (Ed). Diagnóstico neurorradiológico. Rio de Janeiro: Revinter 1999:199-247.

14. Macpherson BC, Macpherson P, Jennett B. CT evidence of intracranial contusion and hematomas in relation to the presence, site and type of skull fracture. Clin Radiol 1990;42:321-326.

15. Gentry LR. Head trauma. In Atlas SW (Ed). Magnetic resonance imaging of the brain and spine, $3^{\text {a }}$ Ed. Philadelphia: Lippincott Williams \& Wilkins 2002:1059-1098. 
16. Kelly AB, Zimmerman RD, Snow RB, Gandy SE, Heier LA, Deck MD Head trauma: comparison of MR and CT-experience in 100 patients. AJNR 1988;9:699-708.

17. Zimmerman RA. Computed tomography of craniocerebral lesion in the abused child. Radiology 1979;10:687-690.

18. Gentry RL. Primary neuronal lesions. Neuroimag Clin N Am 1991;1: 411-432.

19. Gennarelli TA. Cerebral concussion and diffuse brain lesions. In: Cooper PR (Ed). Head lesion. $3^{\text {a }}$ Ed. Baltimore: Williams \& Wilkins, 1993 137-158.

20. Gentry RL, Godersky JC, Thompson B. MR imaging of head trauma: review of the distribution and radiopathologic features of traumatic lesions. AJNR 1988;9:101-110.

21. Mittl RL, Grossman RI, Hiehle JF, et al. Prevalence of MR evidence of diffuse axonal lesion in patients with moderate head lesion and normal head CT findings. AJNR 1994;15:1583-1589.

22. Tokutomi T, Hirohata M, Miyagi T, Shigemori M. Posttraumatic edema in the corpus callosum shown by MRI. Act Neurochir 1997;70:80-83.

23. Paterakis K, Karantana AH, Komnos A, Volikas Z. Outcome of patients with diffuse axonal lesion: the significance and prognostic value of MRI in the acute phase. J Trauma 2000;49:1071-1075.

24. Osborn AG. Primary effects of CNS trauma. In Osborn AG (Ed). Diagnostic imaging brain, $4^{\mathrm{a}}$ Ed. Washington: AMIRSYS 2004:4-41.

25. Gusmão SN, Silveira RL, Arantes A. Lesão axonal difusa In Pereira CU (Ed). Neurotraumatologia. Rio de Janeiro: Revinter 2000:170-175.

26. Kampfl A, Franz G, Aichner F, et al. The persistent vegetative state after closed head lesion: clinical and magnetic resonance imaging findings in 42 patients. J Neurosurg 1998;88:809-816.

27. Andrade AF. Considerações sobre a classificação do traumatismo leve e monitoração da pressão intracraniana no traumatismo craniencefálico moderado e grave [Tese]. São Paulo, 2004
28. Parizel PM, Van Goethem JW, Özsarlak Ö, Maes M, Philips CD. New developments in the neuroradiological diagnosis of craniocerebral trauma. Eur Radiol 2005;15:569-581.

29. Rocha AJ, Silva CJ, Gama HP, et al. Comparison of magnetic resonance imaging sequences with computed tomography to detect low-grade subarachnoid hemorrhage: role of fluid-attenuated recovery sequence. J Comput Assit Tomogr 2006;2:295-303.

30. Braga FT, Rocha AJ, Hernandez G Filho, Arikawa RK, Ribeiro IM, Fonseca RB. Relationship between the concentration of supplemental oxygen and signal intensity of CSF depicted by fluid-attenuated inversion recovery imaging. AJNR 2003;9:1863-1881.

31. Marshall LF, Marshall SB, Klauber MR. A new classification of head lesion based on computerized tomography. J Neurosurg 1991;75(Suppl): S14-S20.

32. Yanagawa $\mathrm{Y}$, Tsushima $\mathrm{Y}$, Tokumaru A, et al. A quantitative analysis of head lesion using T2*-weighted gradient-echo imaging. J Trauma 2000;49:272-277.

33. Lee B, Newberg A. Neuroimaging in traumatic brain imaging: NeuroRx ${ }^{\circledR} 2005 ; 2: 372-383$

34. Huisman TAGM, Schwamm LH, Schaefer PW, et al. Diffusion tensor imaging as potential biomarker of white matter lesion in diffuse axonal lesion. AJNR Am J Neuroradiol 2004;25:370-376.

35. Liu AY, Maldjian JA, Bagley LJ, Sinson GP, Grossman RI. Traumatic brain lesion: diffusion-weighted MR imaging findings. Am J Neuroradiol 1999;20:1636-1641.

36. Ducreux D, Huynh I, Fillard P, et al. Brain MR diffusion tensor imaging and fibre tracking to differentiate between two diffuse axonal lesions. Neuroradiology 2005;47:604-608.

37. Tong KA, Ashwal S, Hoshouser BA, et al. Hemorrhagic shearing lesions in children and adolescents with posttraumatic diffuse axonal lesion: Improved detection and initial results. Radiology 2003;227:332-339. 